\title{
Post-Loop Electrosurgical Excision Procedure Complications in Srinagarind Hospital
}

\author{
Pimjai Maleerat, Bandit Chumworathayi*, Chumnan Kietpeerakool, \\ Sanguanchoke Luanratanakorn, Amornrat Temtanakitpaisan
}

\begin{abstract}
The purpose of this study was to evaluate the prevalence and predictors of post-Loop Electrosurgical Excision Procedure (LEEP) complications in Srinagarind Hospital, Khon Kaen, Thailand. Retrospective chart review was performed for 200 patients undergoing LEEP during January 2012 to February 2013. Their mean age was 45 years-old. Fifty-three $\mathbf{( 2 6 . 5 \% )}$ ) were menopausal. The three most common preceding abnormal cervical cytology were high-grade squamous intraepithelial lesion (HSIL; 50\%), atypical squamous cell cannot exclude HSIL (ASC-H; 10.5\%), and low-grade squamous intraepithelial lesion (LSIL; 10\%). The overall complications prevalence rate was $16.5 \%$ (95\% CI, 11.4-21.6). Complications included bleeding (11\%; 95\% CI, 6.66-15.3), offensive discharge $(4 \% ; 95 \% \mathrm{CI}, 1.28-6.72)$, and pelvic inflammatory disease $(1.5 \% ; 95 \% \mathrm{CI}, 0.18-3.18)$. Only mode of delivery was an independent predictor of post-LEEP complications. Women with previous caesarean sections carried an increased risk of complications by 3.9 times (95\% CI, 1.21-12.56) compared with vaginal delivery. In conclusion, LEEP is generally safe with an acceptable complication rate. Previous caesarean section was the only independent predictor for post-LEEP complications. However, this predictor still needs prudent evaluation as no clear cause-effect relationship was identified.
\end{abstract}

Keywords: Cervical lesion removal - loop electrosurgical excision - complications - risk factors

Asian Pac J Cancer Prev, 17 (4), 2211-2215

\section{Introduction}

Loop electrosurgical excision procedure (LEEP) is initially described by Prendiville et al. (1989) and become an effective method for evaluation and treatment of cervical intraepithelial neoplasia (CIN). (Prendiville et al., 1989; Wright et al., 1992; Lindeque, 2005) The recommended treatments for high grade lesion are excision of the cervical transformation zone by either laser or loop electrosurgical excision procedure (LEEP), (Wright et al., 1992) also called large loop excision of transformation zone (LLETZ), (Prendiville et al., 1989) laser conization (LC), or cold knife conization (CKC). Each of techniques has advantages and disadvantages. (Lindeque, 2005)

LEEP complications prevalence rate ranged from 0.8 to 14.4\% (Prendiville et al., 1989; Lopes et al., 1994; Mitchell et al., 1998; Takac and Gorisek, 1999; Kietpeerakool et al., 2006; Mints et al., 2006) compared with CKC which its complications prevalence had been reported as high as $36 \%$. (Janthanaphan et al., 2009) The procedure is easy to learn, short operation, low cost, preserved an adequate cervix for future childbearing, performed under local anesthesia in outpatient departments and high cure rate. (Prendiville, 1995; Dunn et al., 2004; Kietpeerakool et

\section{al., 2006)}

Although LEEP is a relatively uncomplicated procedure, some complications may occur such as bleeding, offensive discharge, endometritis, pelvic inflammatory disease, bowel or bladder injury. (Dunn et al., 2004) The information of these complications has been used to inform patients before treatment decision. However, due to lack of these complications information gathered together with its predictors in Srinagarind Hospital, this study was done.

\section{Materials and Methods}

After approval from The Khon Kaen University Ethics Committee in Human Research, outpatient charts of all women underwent LEEP as outpatients at the colposcopy clinic of Srinagarind Hospital between January 2012 and February 2013 were reviewed. There were a total of 200 charts included. Age, parity, last parity, mode of delivery, menopausal status, presenting symptoms, underlying disease, contraceptions, types of abnormal smears, histopathologic results, endocervical curettage procedure, numbers and size of specimens, including type of complications, onset of follow-up visits for 
complications were reviewed and recorded for analyses.

LEEP was performed in outpatient setting using local anesthesia, $1 \%$ xylocaine solution is injected in circular fashion around posterior lip of cervix. By first placing the loop at the edge of the lesion ensuring a free margin of 1-2 mm, but if first excision failed, a second or third pass would be done to remove the entire lesion. The edge and bed of the crater was coagulated using $5 \mathrm{~mm}$ ball electrode with a pure coagulation frequency. All specimens were oriented and set in clock position to pathologist. A sanitary tampon was inserted into vagina to be removed after 4 hours. Sexual intercourse was discouraged for 4 weeks. A follow-up visit about 3-4 weeks would be done to counsel patients about their histopathologic result and inquire them about their symptoms and complications they have or had. Prophylactic antibiotics were not routinely prescribed but may be given depending on their clinician's opinions.

Post-LEEP complications was defined as acute complication if occurred within the first 7 days and as late complication if occurred after 7 days but within 4 weeks including; persistent vaginal bleeding by excluding menstrual bleeding, offensive or purulent vaginal discharge, cervicitis, endometritis, pelvic inflammatory disease, and any complications required hemostatic interventions, monsel's paste, vaginal packing, oral antibiotics, and admission as inpatient for parenteral antibiotics, or transfer to operating room.

Statistical analyses were carried out using SPSS computer software. For predictors with a p-value of less than 0.20 in univariate analysis, multiple logistic regression analysis would be used to determine the independent predictor(s). A p-value of $<0.05$ was considered significant. Descriptive statistics with numbers, percentage, and mean \pm SD were also used.
Table 1. Characteristics of Patients Underwent LEEP in Srinagarind Hospital

\begin{tabular}{lc}
\hline Characteristics & $\mathrm{N}=200(\%)$ \\
\hline Menopausal status & \\
Premenopause & $147(73.5 \%)$ \\
Postmenopause & $53(26.5 \%)$ \\
Parity & \\
Nulliparous & $20(10 \%)$ \\
Multiparous & $180(90 \%)$ \\
Mode of delivery n=180 & \\
Vagina & $71(39.4 \%)$ \\
Caesarean & $24(13.3 \%)$ \\
Unknown & $85(47.2 \%)$ \\
Contraception & \\
Tubal resection & $81(40.5 \%)$ \\
None & $74(37 \%)$ \\
Oral pills & $18(9 \%)$ \\
Others & $27(13.5 \%)$ \\
Cervical smear result & \\
HISL & $100(50 \%)$ \\
ASC-H & $21(10.5 \%)$ \\
LSIL & $20(10 \%)$ \\
Others & $59(29.5 \%)$ \\
Histopathologic result & \\
CIN II-III & $82(41 \%)$ \\
CIN I & $55(27.5 \%)$ \\
Cancer & $17(8.5 \%)$ \\
Others & $46(23 \%)$ \\
Margin involved & \\
Negative & $125(62.5 \%)$ \\
Positive & $74(37 \%)$ \\
Unidentified & $1(0.5 \%)$ \\
Size of specimens & \\
< P75 & $55(27.5 \%)$ \\
\hline
\end{tabular}

Table 2. Univariate Analyses of all Potential Predictors for Post-LEEP Complications

\begin{tabular}{|c|c|c|c|}
\hline Variables & $\mathrm{n}(\%)$ & OR $(95 \% \mathrm{CI})$ & $\mathrm{p}$-value \\
\hline Age & & & $0.14 *$ \\
\hline$>40$ & $19(13.87)$ & $0.56(0.25-1.32)$ & \\
\hline$<40$ & $14(22.22)$ & & \\
\hline Parity & & & 0.75 \\
\hline Nulli & $4(20.0)$ & $1.30(0.30-4.44)$ & \\
\hline Multi & $29(16.11)$ & & \\
\hline Mode of delivery & & & $0.004 * *$ \\
\hline Cesarean section & $9(37.5)$ & $4.73(1.34-16.50)$ & \\
\hline Vaginal labor & $8(11.27)$ & & \\
\hline Mode of delivery & & & $0.002 * *$ \\
\hline Cesarean section & $9(37.5)$ & $4.08(1.37-11.48)$ & \\
\hline Vaginal labor + Unknown & $20(12.82)$ & & \\
\hline Last parity & & & $0.18 *$ \\
\hline$<10$ years & $11(22.45)$ & $1.77(0.69-4.37)$ & \\
\hline$\geq 10$ years & $18(14.06)$ & & \\
\hline Menopause & & & 0.24 \\
\hline Yes & $6(11.32)$ & $0.57(0.18-1.53)$ & \\
\hline No & $27(18.37)$ & & \\
\hline Contraception & & & 0.51 \\
\hline Oral contraceptives pills & $4(22.22)$ & $1.51(0.34-5.26)$ & \\
\hline Non-oral contraceptives pills & $29(15.93)$ & & \\
\hline $\mathrm{DM}$ & & & 0.26 \\
\hline Yes & $2(33.33)$ & $2.63(0.23-19.15)$ & \\
\hline No & $31(15.98)$ & & \\
\hline
\end{tabular}


Table 2. Univariate Analyses of all Potential Predictors for Post-LEEP Complications (continued)

\begin{tabular}{|c|c|c|c|}
\hline Variables & $\mathrm{n}(\%)$ & OR $(95 \% \mathrm{CI})$ & $\mathrm{p}$-value \\
\hline $\mathrm{HIV}$ & & & 0.6 \\
\hline Positive & $0(0.0)$ & NA & \\
\hline Negative & $33(17.1)$ & & \\
\hline Pap smear result & & & 0.69 \\
\hline Carcinoma & $1(7.69)$ & $0.40(0.01-2.92)$ & \\
\hline Non carcinoma & $32(17.11)$ & & \\
\hline Symptoms (bleeding, discharge, pain) & & & 0.31 \\
\hline Yes & $3(9.09)$ & $0.48(0.09-1.7)$ & \\
\hline No & $29(17.37)$ & & \\
\hline Numbers of specimens & & & 1 \\
\hline$>1$ & $1(11.11)$ & $0.62(0.01-4.92)$ & \\
\hline 1 & $32(16.75)$ & & \\
\hline Size of specimens & & & $0.19 *$ \\
\hline$>$ p75 & $6(10.91)$ & $0.54(0.17-1.44)$ & \\
\hline$<$ p75 & $27(18.62)$ & & \\
\hline Depth of specimens & & & 0.22 \\
\hline$>$ Mean & $21(19.44)$ & $1.61(0.7-3.83)$ & \\
\hline$<$ Mean & $12(13.04)$ & & \\
\hline Margins of specimens & & & 0.52 \\
\hline Not free + Unidentified & $14(18.67)$ & $1.28(0.55-2.91)$ & \\
\hline Free & $19(15.2)$ & & \\
\hline Pathological diagnosis & & & 0.89 \\
\hline Carcinoma & $3(17.65)$ & $1.09(0.19-4.27)$ & \\
\hline Non-carcinoma & $30(16.39)$ & & \\
\hline Endocervical curettage & & & 0.37 \\
\hline Unremarkable + Abnormal & $33(17.37)$ & NA & \\
\hline Not done & $0(0.0)$ & & \\
\hline Prophylactic antibiotics & & & 0.47 \\
\hline No & $32(17.2)$ & $2.70(0.38-118.32)$ & \\
\hline Yes & $1(7.14)$ & & \\
\hline
\end{tabular}

Table 3. Multivariate Analysis to Determine the Independent Risk Factor

\begin{tabular}{lcl}
\hline Variable & Adjusted OR (95\%CI) & p-value \\
\hline Age $>40$ year-old & $0.42(0.08-2.24)$ & 0.31 \\
Mode of delivery: caesarean section & $3.9(1.21-12.56)$ & $0.02^{* *}$ \\
Last parity < 10 years & $1.11(0.21-5.78)$ & 0.9 \\
Size of specimens $(\geq \mathrm{p} 75)$ & $0.6(0.15-2.5)$ & 0.49 \\
\hline
\end{tabular}

** $=$ equal or less than 0.05

\section{Results}

Two hundred women were reviewed. Mean age was 45 year-old (range 17-78 years-old. $151(75.5 \%)$ had no underlying disease and $6(3 \%)$ were diagnosed as HIV positive before the operation. Endocervical curettage was performed in 190 (95\%) of women who underwent LEEP, in which $149(74.5 \%)$ of their histopathologic results were unremarkable. The clinical characteristics of the patients are summarized in Table 1.

Thirty three $(16.5 \%$; 95\%CI, 11.36-21.64) women had post-LEEP complications. From these, three (1.5\%) Women were admitted as inpatient, one had heavy bleeding need vaginal packing. Two from those three had purulent discharge and pelvic inflammatory disease (PID) needing parenteral antibiotics. Four $(2 \%)$ women returned before follow-up needing Monsel's paste as hemostatic technique for stop bleeding. Ten $(5 \%)$ women had follow-up visit at 3-4 weeks with persistent complications lacking of any previous treatment. The remaining 16
$(8 \%)$ women seeking for treatment before appointment were successfully treated in outpatient setting. Most common antibiotics used in Srinagarind Hospital were quinolone (ofloxacin or norfloxacin) in combination with metronidazole for 10 days.

No immediate complication was found during the study period. Average onset of persistent bleeding was $5.8 \pm 4.5$ days. Average onset of offensive discharge was 10.8 \pm 8.7 days, while that of pelvic inflammatory disease was only $7 \pm 3.5$ days. Fourteen $(7 \%)$ women had prophylactic antibiotics after LEEP. Only one from these had PID. However, in univariate analysis (Table 2) prophylactic antibiotics had only a non-significant association with complications. $(p=0.47)$ Multivariate analysis using a logistic regression analysis to determine the independent risk factor found that women only previous caesarean section increased the risk of complications by 3.9 times (95\% CI, 1.21-12.56) compared with vaginal delivery. (Table 3) 


\section{Discussion}

Loop Electrosurgical Excision Procedure (LEEP) remained one of the effective treatments for cervical premalignant lesions. (Ingkapairoj et al., 2012; WHO, 2014) In this study, the prevalence of postoperative complications following LEEP was $16.5 \%$ (95\% CI, 11.36-21.64), which was just slightly higher than previous reports of 0.8-14.4\%. (Prendiville et al., 1989; Lopes et al., 1994; Mitchell et al., 1998; Takac and Gorisek, 1999; Kietpeerakool et al., 2006; Mints et al., 2006) Persistent bleeding was the most common complications. Almost all of them were of mild to moderate severity. Only one case $(0.5 \%)$ needed admission and vaginal packing for 12 hours.

In Srinagarind Hospital, the most commonly used antibiotics treatment regimen was a 10-days course of quinolone in combination with metronidazole. This seemed to be effective as all complications were subsided and no women come again for retreatment. This was also reasonable because almost all cervical infections are caused by gram negative and anaerobic bacteria. (Chan et al, 2007) The most commonly used prophylactic antibiotics regimen was the same regimen as above. Fourteen (7\%) women received this prescription from their colposcopists. Although, there was no significant association of this predictor with post-LEEP complications, it could reduce the complication down to only 1 out of 14 (7.14\%), which was lower than half of the complication rate in the nonprescribed group (32/186, 17.2\%).

From $16.5 \%$ of all complications, early complications as defined by onset being less than 7 days were found in $9 \%$, and $7.5 \%$ were late complications as defined by their onset being 7 days or more. In the late complications group, the authors found that $10(5 \%)$ or $2 / 3$ of them wait for 3-4 weeks until their appointment reached. They suffered a lot from mild to moderate symptoms without treatment because lacking of understanding and knowledge about the complications and treatment. Fortunately, post-LEEP complications were generally not fatal. In consequence, women who underwent LEEP needed to have comprehensive counseling before, during, and after operation about complications and warning signs for re-schedule of their follow-up visit and treatment. This is very crucial because many people in developing country are lacking of correct knowledge, attitude and practice. (WHO, 2014)

In this study, the authors evaluated the predictors for a higher risk of post-LEEP complications and found that the mode of delivery was only a significant predictor. Women with previous caesarean section carried an increased risk of complications by 3.9 times compared with vaginal delivery. This could be explained by characteristics of the cervix, in women who did not pass any baby via her vagina. Her transformation zone (TZ) is generally hidden inside the os and her cervix is generally hanged up high. These would make a colposcopist difficult to perform LEEP, in order to remove her entire lesion around squamo-columnar junction (SCJ). More contamination in combination with deeper LEEP wound might play their roles, and complications could simply follow the operation in these circumstances.

This is the first study finding out that caesarean section was only the significant predictor for post-LEEP complications. However, modes of delivery were not known in about half of populations. We primarily excluded them from analyses. Nevertheless, when we assumed the unknown as vaginal the result was still similar to the primary analyses with adjusted $\mathrm{OR}=3.74(95 \% \mathrm{CI}$, 1.39-10.11). This information about the association between caesarean section and complications should still be used with caution because there was no clear cause-effect relationship being clearly identified. A prospective comparative study or a large randomizedcontrolled trial comparing prophylactic antibiotics to control for prevention of post-LEEP complications are still necessary (Morrill et al., 2013) and this finding needs to be re-assessed.

In conclusion, LEEP had acceptable complications rate of less than $20 \%$ in Srinagarind Hospital,

\section{References}

Chan KKL, Tam KF, Tse KY, et al (2007). The use of vaginal antimicrobial after large loop excision of transformation zone: a prospective randomised trial. BJOG, 114, 970-6.

Dunn TS, Killoran K, Wolf D (2004). Complications of outpatient LLETZ procedures. J Reprod Med, 49, 76-8.

Ingkapairoj $\mathrm{N}$, Luanratanakorn $\mathrm{S}$, Chumworathayi $\mathrm{B}$, et al (2012). Incidences of cervical intraepithelial neoplasia 2-3 or cancer pathologic diagnoses in patients with a high grade squamous intraepithelial lesion pap smear attending a colposcopy clinic at srinagarind hospital. Asian Pac J Cancer Prev, 13, 6203-6.

Janthanaphan M, Wootipoom V, Tangsinmunkong K, et al (2009). Comparison of success rate and complications of contour-loop excision of the transformation zone (C-LETZ) with cold knife conization (CKC) in high grade lesion (HGL) from colposcopic impression. J Medical Assoc Thai, 92, 1573-9.

Kietpeerakool C, Srisomboon J, Khobjai A, et al (2006). Complications of loop electrosurgical excision procedure for cervical neoplasia: a prospective study. J Med Assoc Thai, 89, 583-7.

Lindeque BG (2005). Management of cervical premalignant lesions. Best Pract Res Clin Obstet Gynaecol, 19, 545-61.

Lopes A, Beynin G, Robertson G, et al (1994). Short term morbidity following large loop excision of the cervical transformation zone. J Obstet Gynaecol, 14, 197-9.

Mints M, Gaberi V, Andersson S (2006). Miniconization procedure with C-LETZ conization electrode for treatment of cervical intraepithelial neoplasia: a Swedish study. Acta Obstet Gynecol Scan, 85, 218-23.

Mitchell MF, Tortolero-Luna G, Cook E, et al (1998). A randomized clinical trial of cryotherapy, laser vaporization, and loop electrosurgical excision for treatment of squamous intraepithelial lesions of the cervix. Obstet Gynecol, 92, 737-44.

Morrill MY, Schimp MO, Abed H, et al (2013). Antibiotic prophylaxis for selected gynecologic surgeries. Int J Gynecol Obstet, 120, 10-5.

Prendiville W (1995). Large loop excision of the transformation zone. Clin Obstet Gynecol, 38, 622-39.

Prendiville W, Cullimore J, Norman S (1989). Large loop excision of the transformation zone (LLETZ). A new method of management for women with cervical intraepithelial 

neoplasia. Br J Obstet Gynaecol, 96, 1054-60.

Takac I, Gorisek B (1999). Cold knife conization and loop excision for cervical intraepithelial neoplasia. Tumori, 85 , 243-6.

Wright TC Jr, Gagnon S, Richart RM, et al (1992). Treatment of cervical intraepithelial neoplasia using the loop electrosurgical excision procedure. Obstet Gynecol, 79, 173-8.

World Health Organization (WHO) (2014). Comprehensive cervical cancer control: a guide to essential practice $(C 4 G E P), 2^{\text {nd }}$ ed. Geneva: WHO Press: 1-364. 